Estudios sobre armas antiguas, arte militar $\mathrm{y}$ vida cultural en oriente y occidente

XXXV (2015), pp. 159-180

ISSN: 0436-029X

doi: 10.3989/gladius.2015.0009

\title{
DE DRAGONES, CASCOS Y SOLDADOS DE FORTUNA EN EL OCCIDENTE ANTIGUO. ACERCA DE DOS OBRAS RECIENTES SOBRE EL MERCENARIADO GALO E HISPANO
}

\author{
ON DRAGONS, HELMETS AND SOLDIERS OF FORTUNE \\ IN THE ANCIENT WEST. REVIEW ARTICLE ON TWO RECENT BOOKS \\ ON GALLIC AND IBERIAN MERCENARIES.
}

\author{
POR \\ Gustavo García Jiménez* y Alberto Pérez Rubio**
}

\begin{abstract}
Graells i Fabregat, Raimon: Mistophoroi Ex Iberias. Una aproximación al mercenariado hispano a partir de las evidencias arqueológicas (s. VI-IV a. C.). Venosa. Maguncia, 2014, Osanna Edizioni, 302 pp., 62 figs. ISBN: 978-8-8816-7456-5.

BARAY, Luc: Les mercenaires celtes et la cultura de La Tène. Critères archéologiques et positions sociologiques. Dijon, 2014, Editions Universitaires de Dijon, 228 pp, 74 figs. ISBN: 978-2-36441-094-7.
\end{abstract}

\section{RESUMEN - ABSTRACT}

La actividad mercenaria en la Antigüedad es uno de los campos de estudio más complejos de la investigación histórica, en buena medida debido a la difícil combinación que existe entre los siempre parciales datos de las fuentes literarias y la arqueología. La reciente publicación de dos monografías dedicadas al mercenario ibérico y celta, a cargo respectivamente de Raimon Graells y Luc Baray, nos brinda una magnífica oportunidad para retomar una vieja discusión siempre latente en el estudio de las dinámicas bélicas y culturales, y que nos permite ahondar en las intrincadas relaciones a larga distancia en el Occidente europeo antiguo.

Research on ancient mercenaries is fraught with problems, being the match between the scarce and partial data provided by the literary sources and the archaeological record a tricky and difficult matter. The recent publication of two books dealing with Iberian and Celtic mercenaries, by Raimon Graells and Luc Baray respectively, offers us an opportunity to dwell on a pervading discussion when studying cultural and military dynamics, and long distance relationships in Ancient Western Europe.

\section{Palabras Clave - Keywords}

Mercenarios; celtas; iberos; celtíberos; La Tène.

Mercenaries; Celts; Iberians; Celtiberians; La Tène.

* C/ Miquel Rosset, 33, 1-1; 17488, Cadaqués (Girona), gust_mei@hotmail.com.

** Personal Investigador en Formación en el Departamento de Historia Antigua, Historia Medieval y Paleografía y Diplomática de la Universidad Autónoma de Madrid. Trabajo realizado en el marco del proyecto de investigación "Entre la paz y la guerra: alianzas, confederaciones y diplomacia en el Occidente mediterráneo (siglos III-I a.C.)" (Ref. HAR2011-27782), Plan Nacional I+D+I, Ministerio de Economía y Competitividad, Gobierno de España, albertom.perez@uam.es. 
El estudio del mercenariado en la Antigüedad está recibiendo en los últimos años una atención renovada, profundizando en el análisis de un fenómeno que, más allá de su dimensión estrictamente militar, implicó un elevado grado de movilidad interregional, con individuos y grupos que habrían recorrido el Mediterráneo antiguo. Se han ido superando además las aproximaciones centradas en el mercenariado griego para poner el foco en otros ámbitos, más "periféricos" si se quiere. En este sentido cabe señalar trabajos como los de Gianluca Tagliamonte y su I Figli di Marte (1994), dedicado al mercenariado itálico en Sicilia y la Magna Grecia; la obra sobre los mercenarios a sueldo de Cartago de Anna Chiara Fariselli (I mercenari di Cartagine, 2002); el acercamiento al fenómeno en Sicilia de la mano de Sandra Péré-Noguès; o en el ámbito de la divulgación el volumen colectivo dirigido por Gustavo García Mercenarios en el mundo antiguo (2013). Dentro de esta línea de interés creciente, es indicativo cómo en una obra de conjunto como es Pratiques et identities culturelles des armées hellénistiques du monde méditerranéen (2011), dedicada al análisis del resbaladizo término de identidad dentro de los ejércitos del periodo helenístico, el fenómeno mercenario recibe buena atención, algo por lo demás inexcusable dado que en buena medida implicó el contacto y coexistencia de gentes con identidades a priori diferentes. Llegamos así a los dos trabajos que aquí nos ocupan, Les mercenaires celtes et la culture de La Tène. Critères archéologiques et positions sociologiques (2014) de Luc Baray y Mistophoroi Ex Iberias. Una aproximación al mercenariado hispano a partir de las evidencias arqueológicas (s. VI-IV a. C.) 2014, de Raimon Graells. Dos obras que parten de presupuestos metodológicos similares, esto es, la confrontación del registro arqueológico para intentar detectar la presencia de mercenarios, celtas en el primero caso, hispánicos en el segundo, pero que llegan como veremos a conclusiones divergentes.

El Dr. Raimon Graells se había asomado ya anteriormente al tema que desarrolla en este libro, destacando trabajos arriesgados pero sugerentes como su propuesta sobre los Mistophoroi ilergetes en el siglo IV a.C.: el ejemplo de las tumbas de caballo de la necrópolis de la Pedrera (Vallfogona de Balaguer-Térmens, Catalunya, España) (2011) o, junto con los Dres. Lorrio y Quesada, el volumen Cascos Hispano-Calcídicos. Símbolo de las élites guerreras celtibéricas (2014). Siguiendo pues la senda que ya había ido trazando, Graells profundiza en un asunto que ha sido fértil en la investigación española ${ }^{1}$, el del mercenariado ibérico - entendiendo ibérico, como bien apunta el autor, desde un punto de vista geográfico, ex Iberias, sin apriorismos étnicos. El acierto de Graells es intentar superar el análisis de las fuentes que hacen mención al mercenariado ibérico para centrar el foco sobre sus posibles rastros dentro del registro material — como de manera mucho más limitada ya hiciesen García y Bellido (1934, 1974) y Luque (1984) con los broches de cinturón-, un testimonio ciertamente elusivo y difícil de aprehender. Mérito tiene por ello su intento, que el autor realiza desde tres acercamientos complementarios, como son el análisis de las posibles evidencias de actividad mercenaria ibérica fuera de la Península — armas y elementos de ornamentación hispanas encontradas en el Mediterráneo-; las posibles evidencias de dicha actividad que podrían atestiguar armas y otros objetos de origen foráneo halladas en Hispania; y, por último, y ahondando en la hipótesis ya presentada en el volumen sobre los llamados cascos hispano-calcídicos, armas hispanas que habrían sido desarrolladas merced a un know-how adquirido a través del mercenariado. Merece la pena destacar el cuidado y completo aparato gráfico incluido, indispensable para el adecuado seguimiento de todo el elenco de evidencia material desgranado en el texto.

1 Desde los seminales trabajos de García y Bellido $(1934,1964,1974)$ hasta las agudas reflexiones de Quesada (1994a, 1994b, 2009) han sido bastantes los acercamientos al tema, y sin ánimo de ser exhaustivos podemos mencionar entre otros a Blázquez y García-Gelabert (1988), Santos (1980, 1981, 1982), Barceló (1991), Gómez Fraile (1999), Gracia (2003), Pliego (2003) o Pelegrín (2004). 
El primer capítulo sirve a Graells para hacer una declaración de intenciones y esbozar un breve estado de la cuestión, además de para aclarar algunos puntos generales pero pertinentes como son por ejemplo la denominación a emplear para hablar del mercenario hispano - mistophoros parece convincente- o el área geográfica considerada, tanto de destino como de origen. A este respecto, dada la vaguedad con que nuestras fuentes definen a los mercenarios hispanos hasta el s. III a. C., solo la información arqueológica, desmenuzada en este trabajo, serviría para aclarar sus posibles zonas de origen, en el Levante peninsular, valle del Ebro y área celtibérica según el autor. La cronología considerada llega solo hasta el s. IV a.C., obviando entrar en la siguiente centuria, muy rica en menciones al mercenariado hispánico para la Segunda Guerra Púnica pero problemáticas desde el punto de vista de su caracterización — ¿mercenarios, aliados, auxiliares...?-. Graells justifica esta omisión ya que su aproximación es fundamentalmente arqueológica y entrar en el s. III a.C. supondría revertir este enfoque en favor de las fuentes, aunque es consciente de que el tema abordado "solo podrá entenderse completamente valorando del mismo modo la actividad de la segunda mitad del s. III a.C." (p. 29). En efecto, aunque su prevención es comprensible, un cuadro completo de los posibles reflejos materiales del mercenariado hispano se hubiera enriquecido con el análisis de aspectos como la aparición recurrente de cascos de tipo Montefortino (García-Mauriño 1993; Quesada, 2004: 72-73) o la generalización del escudo oval en las áreas ibérica y celtibérica a finales del s. III a. C. (Quesada, 2004: 74-84; García Jiménez, 2012: 245-263).

En el segundo capítulo, Graells repasa cronológicamente las menciones en las fuentes sobre el mercenariado ibérico en los siglos V y IV a.C., y hasta la Guerra Inexpiable en 241 a.C., para pasar a plantearse algunas cuestiones relevantes de cara a su posterior análisis del registro material. En primer lugar, ¿dónde desarrollaron estos mercenarios su actividad? Las fuentes solo nombran Sicilia y el Peloponeso - el norte de África también si consideramos que alguno habría acompañado a Agatocles o si vamos hasta el 241 a.C.--, pero el autor considera que es probable que también actuasen en la Italia meridional y quizás en Macedonia, tal y como argumenta más adelante. Se aborda luego brevemente quiénes habrían sido sus empleadores, algo ya respondido en el repaso de las fuentes, para tratar acto seguido de dilucidar dónde se habría producido su enrolamiento. Este se habría realizado en puntos como Gadir, el campamento de El Gandul en Alcalá de Guadaira (Pliego, 2003), Baria, Benicarló ${ }^{2}$ o Emporion, entre otros, actuando como ports of trade tal y como avanzase Quesada (1994a), aunque se echa de menos una mención a Alcácer do $\mathrm{Sal}^{3}$, un yacimiento cuyos materiales, con panoplias muy heterogéneas, apuntan precisamente a un centro reclutador de mercenarios (Quesada, 1994a: 204). Es interesante el apunte sobre la posibilidad de analizar el mercenariado hispánico a la luz de instituciones gentilicias propias del mundo itálico como las vereiia o las sodalitates, un "discurso en construcción" en el que habría que profundizar. El escueto epígrafe sobre Contratos, pago y duración sirve para apuntar uno de los debates clave para entender el posible impacto del mercenariado en sus sociedades, el retorno o no retorno del guerrero. Graells avanza que defiende ese regreso y la importancia que habría tenido en el desarrollo de algunos aspectos de las sociedades de origen, apoyado en la documentación arqueológica ya que comenta que no

2 Este es un punto de reclutamiento novedoso que introduce el autor con datos sólidos articulados a partir de peculiares hallazgos armamentísticos (p. 48 y 194-195) —en particular cascos de distintos tipos (cfr. Graells et alii, 2014: 242)—, si bien generando a su vez importantes interrogantes en cuanto a su conexión con los territorios del interior; en especial la Celtiberia (vid. infra).

3 A diferencia de otros lugares planteados por Quesada (cfr. igualmente Fariselli, 2002: 206-207) como centros de reclutamiento del interior - caso de Cástulo, que el autor rechaza para fechas anteriores a la Segunda Guerra Púnica con flacos argumentos (p. 47 y nota 156) - el de Alcácer do Sal ni siquiera es valorado a pesar de su potencial. 
existen testimonios escritos que relaten el regreso de mercenarios hispanos ${ }^{4}$. Una estimación del volumen de mercenarios hispanos, los otros contingentes junto a los que lucharon y el tipo de combate desarrollado cierran el capítulo. Fuerza de choque, asalto a ciudades y caballería parecen ser los cometidos tácticos que se desprenden de los textos, pero el posible apunte a su participación naval, merced a una lectura de Tucídides (VI.90), nos parece peregrino. Graells comenta que "Tucídides citaba la posibilidad de que los íberos construyeran trirremes en Sicilia" (p. 53), pero el párrafo en cuestión, cuando Alcibíades explica en Esparta los objetivos de la expedición ateniense contra Siracusa, aunque habla de reclutar mercenarios íberos y de construir trirremes empleando la abundante madera de Italia, no dice que sean los primeros quienes construyan las naves. Y tampoco el envío de 20 trirremes con mercenarios celtas e íberos por Dioniso (Xen. Hell. VII.1.20) implica que fueran estos quienes las tripulasen.

El tercer capítulo del libro entra ya de lleno en el análisis del registro arqueológico, comenzando con las posibles evidencias de mercenarios hispanos en el Mediterráneo. Como el autor señala, cualquier pieza de origen hispano no es susceptible de alumbrar a un mercenario, sino que habrá de discriminarse tipológica y cronológicamente y además tener en cuenta "el contexto arqueológico, el marco histórico y las dinámicas de interacción". Los broches de cinturón de garfios son el elemento que más directamente se ha relacionado con el mercenariado hispánico, y Graells realiza un minucioso repaso de estos elementos y de las fíbulas anulares hispánicas dispersas por el Mediterráneo, lo que le permite discernir tres grupos diferenciados. El primero vendría indicado por los hallazgos de broches de Génova, Pisa, Aléria y Nepi, con una cronología de entre 525-450 a.C. y un origen localizado en el Ebro y la Celtiberia, y correspondería a la circulación de objetos de prestigio entre élites militares, ya que los broches se integrarían en el ajuar personal de guerreros itálicos, etruscos o "etrusquizados", sin que pueda hablarse de mercenarios hispanos per se. Hay que destacar la cuidada interpretación que el autor hace del contexto y de los elementos junto a los que se encontró cada pieza, verdadero eje que sirve para aceptar o desechar su vinculación al mercenariado. En ese sentido, las fíbulas anulares, cuyo origen estaría en el nordeste peninsular y por tanto no coincidiría plenamente con el de los broches encontrados en área etrusca, responderían a dinámicas comerciales diferentes. El tercer grupo correspondería a los broches de cinturón encontrados en los santuarios griegos ${ }^{5}$ de Olimpia y Corfú, cuya tipología los emparenta con el área catalana y el Languedoc. La propuesta de Luque (1984) sobre su carácter de spolia hostium es recogida y afinada por Graells, que los considera convincentemente como ofrendas derivadas de la batalla de Himera de 480 a.C. De este mismo encuentro procederían la pareja de cnémides encontradas en la necrópolis de dicha ciudad siciliota (Vassallo, 2014), de clara raigambre hispánica y depositadas junto a los griegos caídos en combate a modo de tropaion, y la cnémide encontrada en Olimpia. A estos materiales se sumaría el disco-coraza también hallado en el santuario olímpico, tradicionalmente identificado como itálico pero que en realidad sería una producción del Mediterráneo occidental con paralelos a finales del s. V y comienzos del s. IV a.C., con contexto similar al de los broches de cinturón y la cnémide, esto es spolia hostium de mercenarios ibéricos caídos en Himera. El repaso a los materiales finaliza con una cabezada de bronce del RGZM, comprada en Italia, pero con paralelos de hierro en la Meseta norte del s. V a.C. en adelante. Harto estimulante es la hipótesis de Naso (2003: 174), que el autor suscribe,

4 Sin embargo, aunque es cierto que no de manera explícita, este retorno sí aparecería sugerido (aunque ya para el s. III a. C.) en Polibio I.69.7, en relación a la revuelta de los mercenarios, con íberos presentes: "cuando los linajes restantes hubieran cobrado y se hubieran retirado a sus países". Igualmente en Livio XXV.30, cuando un hispano al servicio de Roma trata de persuadir al también hispano Moerico para que entregue Siracusa con estas palabras: "podía ser caudillo de sus paisanos, tanto si quería servir en el ejército romano como si prefería volver a la patria".

5 Acerca del depósito de armas en santuarios en el Mediterráneo antiguo, véase en particular Gabaldón, 2004. 
sugiriendo que podría tratarse de una producción siracusana, en relación a la cita de Diodoro (XIV.41.4) sobre la producción de armas para los mercenarios de Dioniso el Viejo copiando los modelos de cada contingente ${ }^{6}$. Pasando de los realia a la iconografía, existen dos posibles imágenes de mercenarios ibéricos fuera de la Península. La primera sería el guerrero pintado sobre una lastra de Cerveteri fechada a finales del s. VI/comienzos del IV a.C., que se protege con un disco-coraza fijado con el sistema de cuatro correas, exclusivo de los ejemplares ibéri$\cos ^{7}$. No está clara la identidad del personaje, y quizás ese empleo del disco-coraza engarzaría con la interpretación sobre los ganchos de cinturón hallados en área etrusca. La segunda sería una representación vascular sobre una crátera de figuras rojas ápulo-lucana (Kunsthistorisches Museum de Viena, $n^{\circ}$. inv. 918) en la que aparecen dos guerreros armados con elementos heterogéneos, que Graells interpreta como posibles mercenarios. Uno de ellos porta un aspis típico del área lucana y un casco calcídico, lo que permitiría identificarlo como un mercenario campano o samnita. El otro va desnudo, salvo un disco-coraza detalladamente pintado que para el autor solo cabe identificar con los del tipo 6c del área celtibérica de la segunda mitad del s. V y del s. IV a.C. (Graells, 2014: 145-148); se cubre con un casco tipo Pilos y cuenta con un cinturón de láminas, elemento marcial propio de samnitas y lucanos. Este guerrero sostiene tres lanzas - jabalinas más bien-, componente con el que según el autor el artista intentaba "demostrar un modo de combate inusual que acentuaba una condición especial que no encuentra correspondencia en la cerámica suritálica" (p. 78), aunque en cambio sí existen asociaciones de tres o más puntas de lanzas en algunas panoplias destacadas de la Meseta norte. Hemos aquí de disentir, ya que sí existen varias representaciones de guerreros lucanos con tres lanzas/ jabalinas en algunos frescos conservados en el Museo Archeologico Nazionale de Paestum (Pontrandolfo et alii, 1998). Así, en la tumba 58 de la necrópolis pestana de Andriuolo, en un duelo entre dos guerreros arbitrado por una esfinge, uno de ellos sostiene dos jabalinas en la mano izquierda y una tercera en la derecha, además de haber lanzado ya otra que ha herido a su contrincante en el vientre. Este, a su vez, blande una lanza pero ya habría arrojado dos jabalinas, una en el suelo y la otra que ha impactado en el muslo del primer guerrero. Otros duelos como los representados en la tumba 1 de la necrópolis de Arcioni o en la tumba 7 de la necrópolis de Gaudos demuestran también ese intercambio de jabalinas, y en las escenas de "regreso del guerrero" este porta a veces sendas lanzas/jabalinas (tumba 4 de la necrópolis de Vannullo o tumba 61 de la de Andriuolo). De hecho, los modelos de combate para la Italia antigua avanzados últimamente apuntan a la importancia del combate de proyectil previo al cuerpo a cuerpo, modelo perpetuado en las descargas de pila de la legión romana republicana, y que sería bastante similar al de las comunidades ibéricas y celtibéricas (Quesada, 2006). Este caveat no invalida la posibilidad de que el personaje sea un mercenario celtíbero, dado su disco-coraza, pero sí hace menos segura esa identificación. El capítulo se cierra con una contextualización de las evidencias de realia antes repasadas, insertando los ejemplos de posibles spolia hostium en los patrones de ofrendas realizadas por los tiranos siracusanos y su intencionalidad política, para afirmar con un discurso coherente que los materiales ibéricos encontrados en santuarios griegos serían testimonios de la batalla de Himera.

El cuarto capítulo del libro está dedicado al análisis de las armas griegas encontradas en la Península. Como bien puntualiza Graells, la presencia de armas extrapeninsulares no implica

6 Sin perjuicio de que se trate de una pieza falsa. Naso (Ibid.) menciona su procedencia itálica acompañándola de un interrogante "(?)", y añadiendo su correspondencia a una colección privada. Como pieza hispánica, afín a lo que su tipología sugiere, sería realmente extraña su fabricación en bronce (Quesada, 2005: 121).

7 Otro ejemplo de disco-coraza de tipo Mediterráneo occidental sería el representando en la lastra de la tumba 58A de la necrópolis Andriuolo de Paestum, como el mismo Graells indica en otra publicación (2014: 144-145) pero no recoge aquí. 
mercenarios de ese origen ni tampoco la actuación de mercenarios ibéricos en dichas zonas. Se estudian en primer lugar los cascos corintios que han aparecido en área tartésica con una cronología de los ss. VII y VI a. C., y que probablemente haya que ver más como fruto de la circulación de guerreros que del comercio empórico, quizás en el marco de una protección comercial que serviría como semilla para el ulterior reclutamiento estructurado que ya documentan las fuentes, una intuición muy sugerente puesto que es complicado imaginar esa segunda fase ex novo, sin "ensayos" previos. En lo que respecta a las puntas de flechas de tipo Olimpia, aunque de momento no podemos definir su origen, su concentración en el nordeste peninsular y el Golfo de León por un lado, y en Sicilia por otro, refrendaría un contacto de naturaleza militar entre ambas zonas, con Massalia y Emporion vertebrándolo. El capítulo quinto está dedicado a las panoplias y armas etruscas de los ss. V-IV a.C. encontradas en la Península, harto escasas, ya que se restringirían a los elementos de carro hallados en la llamada tumba "Cazurro" de Ampurias, de interpretación difícil, y a dos cascos del pecio de Les Sorres del s. IV a.C. Según Graells, estos cascos serían otra muestra de esa circulación de elementos militares entre el Golfo de León y Etruria que para la centuria anterior habrían evidenciado los broches de cinturón encontrados en el área etrusca, revitalizada en el s. IV a.C. por los conflictos de Sicilia y la Magna Grecia.

El sexto capítulo analiza los elementos de influencia céltica en el Levante peninsular, discutiendo en su primera parte acerca de posibles importaciones armamentísticas - a partir de un estudio monográfico del armamento lateniense peninsular (García Jiménez, 2012) - como la espada de La Pedrera, la de la sepultura D de Quintanas de Gormaz (vid. infra) o la sepultura $7 \mathrm{de} \mathrm{Baza}^{8}$, además de los cascos de hierro —a los que añade interesantes aportaciones - o los umbos bivalvos peninsulares; tema en el que coincide con Baray. La segunda parte del capítulo se centra en otros materiales distintos a las armas, de los que destaca los raros ejemplos de broches de cinturón calado ${ }^{9}$, los brazaletes de vidrio y, sobre todo, las piezas discoidales de pasta vítrea. Estos últimos son un elemento especialmente atractivo que el autor ofrece para su discusión a partir de un reciente estudio de Diliberto y Lejars (Diliberto y Lejars, 2013) que relaciona estas piezas de juego - fechadas en los siglos IV y III a.C.- - con las élites del mundo celtoitálico, quienes las tomarían por influencia de los pueblos de la Italia central, y que vincula con la movilidad individual fuera de estos ámbitos. Graells añade al discurso un importante número de ejemplares de este tipo de fichas procedentes de la península ibérica y repartidos particularmente en el litoral mediterráneo, especialmente en el sureste — principalmente el área bastetana - y en yacimientos en la proximidad de los puertos de embarque de mercenarios como Villaricos, Alicante o Ampurias. Estos datos abren sin duda un interesante panorama acerca de otros elementos de transmisión distintos a los habitualmente tratados por la historiografía, pero hay que objetar aquí al autor que los desvincule arbitrariamente de los circuitos comerciales, en parte espoleado por el comportamiento que mencionan Diliberto y Lejars para las piezas transalpinas, que corresponden a otra realidad sociocultural muy distinta

8 Probablemente el discurso pueda enriquecerse también en sentido inverso, con materiales latenienses hispánicos en otros puntos del Mediterráneo occidental, a partir por ejemplo de la espada de Castellonchio, publicada en un reciente trabajo de T. Lejars (2014: 404-405 y fig. 3) posterior al libro de Graells — pero que este ya menciona; p. 136-, o incluso los ejemplares de Ensérune o Pech Maho (vid. infra; cfr. García Jiménez, e.p.).

9 Que en este caso no tienen cabida en el trabajo de Baray, pese a dedicar un espacio muy notable a la discusión sobre las producciones e interpretaciones locales de este tipo de broches "célticos" (vid. infra). Graells hace hincapié acertadamente en su influencia a partir de modelos conocidos en el norte de Italia y el ámbito suralpino — pese a no corresponder a ninguna de las variantes conocidas (Baray, 2014: 56-64) - ya muy transformados en los casos de los ejemplares de La Osera y la sep. 13 de Osma — diríamos que hasta extremos exagerados: están al revés, con los garfios situados en la base, tienen sujeciones en la placa y no en la base, y en el caso del ejemplar de Osma, se combina con una pieza hembra de tipo hispánico; cfr. García Jiménez, 2012: nota 559 -. 
a la hispánica. De igual modo, su interpretación aparece limitada innecesariamente al mercenariado, algo que Diliberto y Lejars (2013: 456) no plantean sino como una más de las distintas fórmulas de movilidad que explicarían la difusión de estos materiales y aquello que representan. Curiosamente, una perspectiva mucho más cercana a esto último la veremos reflejada en el libro de Baray (vid. infra). Ya al final de este capítulo, el autor incide en que existirían dos vectores distintos de la influencia céltica sobre la actividad de los mercenarios hispánicos: uno procedente del ámbito transalpino occidental, que explicaría la presencia de cascos y otros elementos como los broches de cinturón, y otro celtoitálico en parte filtrado por la vía etrusca y en parte por la de la Italia meridional, el Adriático y el ámbito epirota-macedonio; regiones todas ellas con una fuerte actividad mercenaria.

Esa participación mercenaria ibérica en área ápula o en la órbita epirota-macedonia que se sugiere en el anterior capítulo podría ser refrendada examinando algunos elementos con ese origen, como serían las muserolas de bronce de tipo macedonio encontradas en la necrópolis de La Pedrera y otros dos ejemplares de procedencia desconocida depositados en el MAC y en el Museo de Valencia. Estos bozales solo encuentran correspondencia en tumbas de alto estatus de Macedonia y Apulia, y dado su simbolismo parece convincente pensar en una obtención fruto del intercambio de bienes de prestigio o como botín, siendo pues plausible que sus poseedores hubiesen servido militarmente en esos ámbitos. Otra serie de elementos diversos - fragmentos de sítulas, una crátera, algunas asas metálicas, cinco entalles de pasta vítrea, alguno con una iconografía aparentemente epirota, como el supuesto moloso de un escarabeo de la tumba 70 de Coimbra de Barranco Ancho o el águila de la tumba 10 de Galera- son interesantes por sus contextos de aparición en tumbas singulares, y para el autor responderían a esa comunicación particular entre el área ápulo-epirota-macedonia y la Península. Aunque sin refrendo en las fuentes, se trata de una hipótesis sugerente, si bien pendiente de elementos de mayor enjundia que la sustenten. Los elementos militares de filiación suritálica son abordados en el capítulo octavo, estando limitados de momento a un fragmento de cinturón samnítico del poblado de Puig de la Nau, de la primera mitad del s. IV a.C., además de otro ejemplar en curso de estudio procedente del oppidum del Turó del Montgrós (El Brull) ${ }^{10}$,y una coraza anatómica suritálica de cronología similar, rescatada en un hallazgo submarino en Almuñécar, y que Graells sugiere testimonio o bien de la actividad de mercenarios campanos al servicio púnico o bien del ajuar recogido por un régulo local en su actividad mercenaria extrapeninsular. La contextualización de estos hallazgos sirve al autor para exponer su tesis acerca de los elementos presentes en los ajuares militares de La Pedrera - falcata del sureste, espada de La Tène I, casco céltico noralpino, bozales de tipo macedonio, etc.—; a su entender, estos serían fruto de la actividad mercenaria en el sur de Italia, único lugar que explicaría la reunión de objetos de procedencia tan heterogénea ${ }^{11}$, al entrar en contacto mercenarios ibéricos, celtas y

10 Al que el autor apunta en su trabajo y ha sido confirmado muy recientemente (cfr. García Jiménez y Graells, e.p.; nota 31$)$.

11 Aunque discrepamos con el autor precisamente en este punto en lo que refiere a esa reunión de elementos en suelo itálico y traídos luego a la Península (Graells, 2011: 138 y fig. 50). No hay duda de que se trata de tumbas de personajes correspondientes a las élites, ecuestres si se quiere, pero la llegada de elementos de prestigio tendría que ver más con la capacidad de estos de acumular bienes como resultado de las redes diplomáticas de las que forman parte que con su presencia física en Italia —o al menos con su recopilación de todos los componentes allá-. Elementos como la falcata son en efecto raros en el nordeste peninsular (Quesada, 1997: 76-78), pero en todo caso parecen concretarse siempre en momentos afines a los de la panoplia de La Pedrera, a veces en combinación con espadas La Tène en los mismos contextos (e.g. Can Rodon de 1'Hort o Puig de Sant Andreu; García Roselló et alii, 1998: 315 y fig. 3; Sanmartí 1994: 340), o en momentos algo anteriores, como los casos de Ensérune (Schwaller et alii, 2001: 175) y probablemente el de Mianes (García Roselló et alii, 1998: 315). Ya hemos defendido también anteriormente la correspondencia de las espadas La Tène de este tipo al nordeste peninsular en esta fase (García Jiménez, 2012: 99-101; desde LT B2) — apenas a un centenar y medio de kilómetros sin obstáculos - y la tendencia a la renovación constante de este tipo de armas, que refleja una conexión con 
campanos, apoyándose también en la mentada crátera de Viena y en la producción hispana de armas de inspiración suritálica que más tarde aborda.

El capítulo noveno está dedicado a la cuestión de la moneda, analizándose los tesorillos del levante peninsular para los ss. VI y IV a.C., cuando la moneda funcionaría más como objeto de prestigio y tesaurización que como medio de cambio. Su relación con el retorno de mercenarios entroncaría con ese carácter de objeto de prestigio, similar al de las armas o vajillas metálicas foráneas, con los tesoros con moneda siciliota junto con acuñaciones foceomasaliotas del nordeste peninsular indicando un circuito similar al esbozado para los ganchos de cinturón de área etrusca y las puntas de flecha de tipo Olimpia, mientras que los tesoros con moneda sículo-púnica del sureste indicarían en cambio un retorno directo. Una opinión bien distinta a la que como veremos esgrime Baray respecto a los ejemplos de estáteras de Filipo II encontrados en la Céltica y su posterior imitación.

Tras el repaso a las posibles evidencias materiales de actividad mercenaria ibérica realizado entre los capítulos tercero al noveno, el décimo apunta a un sabroso corolario, la posibilidad de que se hubiesen desarrollado armas en la Península merced al know how adquirido tras siglo y medio de mercenariado, puesto que hablamos de producciones que arrancarían en la segunda mitad del s. IV a.C. Estas se dividirían en dos grupos, los cascos hispano-calcídicos celtibéricos (Graells et alii, 2014) y la cresta metálica ${ }^{12}$ y corazas de discos con pteryges del sureste ${ }^{13}$. Respecto al primer grupo, para el autor sus características morfológicas y técnicas hacen que se trate de producciones desarrolladas en la Península a partir del conocimiento adquirido in situ en la Italia meridional oriental, donde mercenarios hispánicos habrían tenido acceso a los modelos de inspiración, sin perjuicio de que su presencia no esté recogida en las fuentes ${ }^{14}$. Hipótesis sugerente, aunque a nuestro entender parece más plausible considerar Sicilia como lugar de interacción, también en el plano de la adopción y desarrollo de nuevos tipos armamentísticos, ya que sabemos expresamente que en la isla coincidieron mercenarios hispanos e itálicos y que Dioniso el Viejo hizo que se reprodujeran las panoplias de cada contingente (vid. supra). Una cuestión que nos surge es el porqué de la ausencia en la Celtiberia de ajuares singulares, con materiales como los de La Pedrera o el área bastetana, si aceptamos el desarrollo de los cascos hispano-calcídicos como fruto de contactos de guerreros de esta zona en el Mediterráneo central ${ }^{15}$. En cuanto al segundo grupo de producciones, en las que engloba pero

el mundo céltico en cuyo marco no es impensable la presencia de un casco La Tène (Ibíd.: 317). A todo ello, no estamos negando la existencia de lazos con la región suritálica — por otro lado evidentes en otros materiales como las muserolas o la sítula de bronce - y el mundo del mercenariado, sino tan solo matizando que estos deberían enmarcarse en el sino de otras relaciones de distinta índole de las que no debería excluirse (vid. infra).

12 Un gran detalle de calidad es la interpretación de la cresta del casco de la sep. 277 de El Cigarralejo (Cuadrado, 1989: 111; Quesada, 1997: 552) como influencia de las producciones suritálicas siguiendo y ampliando una propuesta de A. Cherici (2007: 241); alternativa verdaderamente atractiva y muy distinta a la que suponía su tradicional interpretación como remate de un casco de materia orgánica.

13 No hubiese estado de más incluir en este apartado, siquiera de manera breve, una reflexión sobre un arma tan emblemática como la falcata — apenas mencionada en el apartado dedicado al armamento de La Tène - , cuyo origen pudo haber estado también en la adopción de tipos itálicos por mercenarios ibéricos (Quesada, 1991: 520; 1997: 160-161).

14 Graells sugiere que las fuentes para el s. IV a.C. bien podían haber etiquetado a los mercenarios celtíberos como "celtas", y de ahí que quizás cuando se hable de mercenarios celtas en la Magna Grecia se englobase tanto a aquellos provenientes de la Cisalpina como a otros de Iberia. Si bien parece que antes de la Segunda Guerra Púnica los "celtas" de

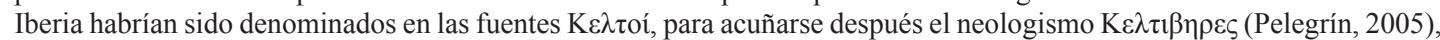
pensamos que la efervescencia de la actividad militar gala durante el s. IV a.C. en Italia central (Bourdin, 2011) hace mucho más probable que estemos ante galos cisalpinos, mucho más familiares y reconocibles en ese momento y lugar que

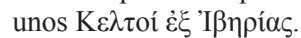

15 Con independencia de si, como afirma el autor de forma algo drástica, "no coincidirían las áreas de mayor contacto comercial con las de mayor impacto mercenario" (p. 195), puesto que el autor afirma repetidamente la captación de estos objetos singulares por otros medios relacionados exclusivamente con la actividad militar. 
solo menciona los prometopidia, destaca la aguda reconstrucción de las placas de la tumba 350 de La Osera y de la tumba 400 de El Cabecico del Tesoro como remates de ptéryges, integrando estos elementos en esa capacidad de las élites militares peninsulares de adoptar elementos foráneos. Se trata este del punto quizás clave del discurso de Graells, por todas las implicaciones que esta adopción supone, y que habrían superado el mero campo material de la indumentaria para entrar en el de los símbolos y la organización.

Es este pues un libro valiente, que asigna al mercenariado hispánico un papel de primer orden en el desarrollo de sus sociedades de origen, merced a procesos de aprendizaje técnicos e ideológicos realizados en el Mediterráneo central que luego se trasladan a sus solares, asumiendo el regreso de un volumen elevado de guerreros (contra Quesada, 1994a) y una contratación casi ininterrumpida de los mismos. Así, en el debate sobre si lo que viajan son personas u objetos, que como veremos será un eje en la exposición del libro de Baray, Graells se decanta por un alto grado de movilidad de estos grupos guerreros, frente a visiones más escépticas. Tanto su propuesta para la transmisión de objetos de prestigio, ajenos a los circuitos comerciales habituales, en virtud de relaciones de $\xi \varepsilon v i ́ \alpha$ o $\varphi \imath \lambda i ́ \alpha$ de los mercenarios hispánicos con otros compañeros de armas, como la del establecimiento de agentes extranjeros en la Península para la contratación, son sugerentes líneas de investigación en lo tocante a las relaciones culturales en el Occidente mediterráneo, que nos permiten atisbar un mundo mucho más dinámico e integrado de lo que normalmente se conceptúa. Sin embargo, el mundo púnico, con Cartago no lo olvidemos como principal reclutador de mercenarios hispánicos, está prácticamente ausente en el rastreo de trazas materiales de la actividad mercenaria que Graells realiza, salvo en el apartado numismático. Es este un aspecto que sugiere una futura línea de investigación a añadir a las ya trazadas en estas páginas.

El trabajo de Luc Baray sin duda podría encuadrarse en esa corriente escéptica a la que alude Graells, y constituye no exactamente el polo opuesto de la publicación de este último, sino más bien la otra cara de la misma moneda: una advertencia de lo escurridizos que pueden ser los datos arqueológicos cuando se trata de enlazarlos directamente con el mercenariado. En este caso, el volumen se dedica al análisis arqueológico de los datos relacionados con el mercenario "celta", cuestión que lleva implícita una complejidad extraordinaria, en tanto a que no existe una cultura material céltica unitaria, superada ya la vieja ecuación unívoca entre la cultura de La Tène ${ }^{16}$ y el territorio céltico. El autor no esconde en absoluto su escepticismo, sino que lo saca a relucir ya desde sus primeras líneas mediante un planteamiento sólido en el que se tiene en cuenta, además, la multipolaridad de la cultura de La Tène. En efecto, la presencia de elementos célticos en territorios ajenos no sería a priori de naturaleza distinta a la de elementos mediterráneos en territorio céltico, y en definitiva no puede ser asociada per se con la actividad mercenaria ${ }^{17}$. Y sin embargo, la historiografía ha caído en esta asunción repetidamente, en buena parte espoleada por una cierta inercia derivada de la consabida relación del mundo céltico con las migraciones masivas, que a menudo conllevan una carga interpretativa relacionada con la búsqueda de refrendos arqueológicos de la presencia céltica en los territorios de destino o de la presencia de elementos propios de estos territorios en suelo

16 El debate sobre la "celticidad", con posturas que oscilan desde el celtoescepticismo a la celtomanía, ha generado abundante literatura en las últimas dos décadas, véase entre otros Collis, 1996, 1997, 2003; Megaw y Megaw, 1996, 1998; James, 1998, 1999; Ruiz Zapatero, 2004, 2010; Karl y Stifter, 2007; Anthoons y Clerinx 2007. Uno de los puntos más apreciables del trabajo lo define el autor al emplear el adjetivo "lateniense", por ser neutro, en vez de "céltico", que tiene una connotación étnica fuera de lugar, una cuestión que el autor tiene muy presente para no caer en falacias argumentales.

17 Con argumentos similares y en relación a las migraciones célticas a la península ibérica (aunque no al mercenariado), García Jiménez, 2012: 378-382. 
céltico (Rapin, 2004) ${ }^{18}$. Si bien es cierto que los textos clásicos aluden frecuentemente a la participación de contingentes mercenarios celtas en el Mediterráneo occidental y oriental, la correlación de las fuentes clásicas con la arqueología no es tarea fácil, y en consecuencia debe ser sometida a revisión constantemente. Y, de hecho, así lo hace, aunque en algún momento a lo largo de la obra de Baray da la sensación de que esa lectura positivista sobre el mercenario celta es la dominante en la actualidad, algo de lo que no estamos en absoluto convencidos. En cualquier caso, el trabajo que aquí nos atañe se enmarca en un proyecto mayor que deriva de la tesis de habilitación a HDR del autor y que está articulado en tres volúmenes (arqueología, fuentes escritas e interpretación socio-antropológica respectivamente) del que este no es sino el primero, por lo que habrá que esperar a los restantes volúmenes para contar con un discurso completo.

Tras el explícito capítulo introductorio, un escueto apartado nos deja entrever precisamente algunos datos en relación a su estudio sobre los textos literarios que tratan sobre el mercenariado céltico. La imagen que nos dibuja es rápida pero concisa, y con el apoyo de un mapa y algunos gráficos, nos permite hacernos con un resumen de ese prometedor segundo volumen, en el que evidencia un vuelco en la proporcionalidad de las citas marcando una fuerte actividad en el Mediterráneo occidental en las menciones antiguas hasta finales del siglo III a.C., para irse decantando hacia Oriente a partir de inicios de ese mismo siglo. Uno de los puntos más importantes, que está indudablemente tras el objetivo de este bloque, es el anuncio de la imposible distinción arqueológica entre el mercenario y el auxiliar ${ }^{19}$, un tema subyacente en la abundante pero a menudo superficial atención que el tema del mercenariado celta ha suscitado, según el minucioso análisis del autor, en la historiografía anterior.

El siguiente capítulo constituye uno de los bloques principales de la obra y se dedica directamente al análisis de los contextos arqueológicos susceptibles de ser relacionados con mercenarios (o que así han sido interpretados en alguna ocasión), un método de análisis similar al empleado por Graells. Es este uno de los capítulos más interesantes, abordando la cuestión a través de tres ejemplos con una muy desigual atención entre ellos: los escudos ovales, las hebillas de cinturón y las ornamentaciones de vainas con liras zoomorfas. La breve mención al escudo de Kasr el-Harit ${ }^{20}$ (aunque prescindible por su ya totalmente descartada relación con el mundo céltico; cfr. Bishop y Coulston, 2006: 61-62), antecede a la mucho más jugosa dis-

18 Migraciones y mercenariado céltico son conceptos a menudo entrelazados. El uno a veces no se comprende sin el otro. Una de las incógnitas más persistentes en cuanto a la movilidad céltica es el tema de las migraciones negociadas (Peyre, 1992: 28; Bourdin, 2011: 22-24) y, en dicho sentido, el caso de los gaesati es uno en los que más se ha centrado la atención historiográfica (Ibíd. y 2012, 605-606, 643 y 727; Péré-Noguès, 2007: 355-357; Szabó, 1991: 334). Los gaesati son, según Polibio (II.22.1) originarios del valle del Ródano y los Alpes, y fueron llamados a la guerra en Italia a iniciativa de las tribus cisalpinas que combatieron contra Roma entre el 238 y el 221 a.C. Su vinculación con el mercenariado es tal, que el propio Polibio (Ibíd.) apunta que el vocablo no refiere a un pueblo en sí mismo sino a su condición de combatientes a sueldo. El nombre procede, según la tradición, del uso del gaesum, que en principio vendría a definir un tipo de arma arrojadiza, probablemente de tipo pilum (Serv., Aen. 7.664; cfr. Rapin, 1988: 88), lo que en nuestra opinión es algo raro teniendo en cuenta lo poco habitual de las armas arrojadizas en las panoplias latenienses del interior en esta época (Lejars, 2008: 170). Paradójicamente, sí es más frecuente en territorio cisalpino, aunque en especial en una fase anterior (Ibíd.: 139-142 y 2014: 410-411 y 420), de modo que quizás habría que entender el término gaesati en otro sentido: bien como "portadores de lanzas", que sería una expresión ya muy genérica, o bien con otras acepciones relacionadas con su fuerza o coraje (cfr. Bourdin, 2011: 24).

19 El mismo problema se halla a menudo en las propias fuentes, también respecto a los mercenarios hispánicos, como más arriba apuntábamos. Sobre la cuestión de los auxiliares "célticos" en Occidente desde el punto de vista arqueológico, véase Pernet, 2010; con excelentes resultados. También en este trabajo se discute la delgada línea que separa ambos conceptos (Ibíd.: 27-28).

20 Se trata de un escudo conservado completo, con todos los elementos lignarios que lo componen. Su forma convexa lo delata como una producción romana, pero además su excelente conservación sirve como ejemplo comparativo respecto a la información que nos ofrece Polibio (VI.23) sobre la composición del scutum romano. 
cusión acerca del escudo de Camarina, conocido a través de un espléndido estudio de André Rapin (2001), y a la posterior reflexión sobre los primeros umbos bivalvos y, en definitiva, sobre el escudo oval y sus complejas atribuciones étnicas. La identificación lateniense del escudo de Camarina, esculpido en un bloque de piedra procedente de los restos de una muralla interna de la ciudad, no ofrece dudas (superficie plana, dimensiones y quizás una cobertura para la spina), y ha sido fechado en base a datos tipológicos hacia finales del siglo V a.C., de modo que la relación con el mercenariado celta en la Sicilia de la época no parece tener discusión ${ }^{21}$. Baray acepta la interpretación como uno de los escasos ejemplos arqueológicos relacionados con el mercenariado celta y se pregunta, siguiendo el hilo del estudio de Rapin, por los umbos bivalvos como posibles indicadores de la actividad mercenaria, considerando su notable dispersión hacia el Mediterráneo, incluyendo la península ibérica. Al margen de alguna importante errata, como fechar los umbos de contextos célticos a mediados del siglo IV a.C. cuando corresponden a la segunda mitad del V a.C.-inicios del IV a.C. (LT A) ${ }^{22}$, se aprecia una cierta paradoja en la comprensión del fenómeno de las producciones hispánicas, sobre las que ya llamó la atención Quesada (1997: 540-541) y en las que se ha insistido repetidamente (Quesada, 2004: 77-79; García Jiménez, 2012: 202-205 y 238-240; García Jiménez y Quesada, 2015; García Jiménez e.p.). Por una parte, se pasa por alto la uniformidad tipológica de los ejemplares hispánicos, sensiblemente distinta a los ejemplares célticos (por ejemplo en sus sujeciones en la concha y no en las aletas, o en el mayor desarrollo de los apéndices), que contrasta con la variedad casi experimental de los ejemplares continentales y habría sido el pretexto perfecto para acentuar el componente local que tanto valora el autor y que efectivamente tiene en cuenta para el caso del umbo de Gualdo Tadino (Vitali, 2003: 77 y fig. 9). Por otra parte, hay ciertos errores de apreciación en la cuestión cronológica, que si bien considera la posterioridad de los ejemplares hispanos, no contempla que estos se prolongan mucho más allá de mediados del siglo IV a.C. y llegan a producirse con cierta continuidad hasta alcanzar sin duda el siglo II a.C., tal y como atestiguan ejemplares como los de Pozo Moro, Arcos de la Frontera, Villaricos o El Romazal (García Jiménez y Quesada, 2015²3). En cualquier caso, los bivalvos peninsulares no valdrían como testimonio del mercenariado más allá de un momento

\footnotetext{
21 Si bien no está exenta de ciertos problemas, puesto que las fuentes escritas no mencionan explícitamente contingentes célticos en los ejércitos púnicos hasta el conflicto contra Timoleón (Diod. XVI.73.3; Péré-Noguès, 2007: 354 y 356; Fariselli 2002, 242), y en esta época es ya algo tarde para este tipo de escudos. Aun así, las lagunas en los hallazgos arqueológicos coetáneos (LT B1) (Rapin, 2001b: 273; 2007: 243-248) apenas permiten estar seguros de que no existan formatos similares en esta época - la "misteriosa" desaparición teórica de los umbos bivalvos en LT B1 para reaparecer con mayor fuerza en LT B2 nos parece, como poco, discutible. Algo más acorde sería la contratación de mercenarios celtas desde el bando siciliota, puesto que hay referencias a ellos al menos desde el año 369 a.C., en manos de los tiranos de Siracusa (Diod. XV.70.1; Xen., Hell.VII.1.20-22; cfr. Péré-Nogués, 2007: 354-356; Szabó, 1991: 333) y existe un cierto consenso en su empleo incluso anterior merced a la política de expansión itálica de Dionisio el Viejo y su contemporaneidad con las migraciones célticas a Italia (Diod., XIV.113.1). Otro problema, que el propio Rapin ya apuntaba y no fue capaz de resolver (Rapin, 2001: 293-294), es el hecho de que un escudo céltico, aunque pudiera hacer referencia a mercenarios, figure en la muralla de una ciudad siciliota (en principio, los escudos en murallas tienen un sentido apotropaico que dificultaría la interpretación de la representación de un escudo ajeno). A priori, lo lógico sería que su contexto tuviera relación con edificios públicos y spolia, pero dado que la ciudad pudo pasar de manos griegas a la tutela púnica y viceversa en distintas ocasiones, la explicación podría tener relación con la política de reubicación de mercenarios de Dionisio el Viejo (Péré-Noguès, 2013: 36).

22 En este punto el autor sigue ciegamente la investigación de Rapin, pero bien podrían haberse añadido otros ejemplos de umbos contemporáneos - e.g. Novo Mesto (Knez, 1966: lám. 3, 1-2) o Dürrnberg (Egg et alii, 2009; que incluye otras piezas menos conocidas) - que habrían ayudado a rellenar algunos espacios en el mapa y enriquecer la discusión (cfr. igualmente Vitali, 2003: passim, y Lejars, 2014: 407 en relación a la representación iconográfica de uno de estos umbos en una crátera de Volterra, de cronología posterior).

23 Al que cabe añadir otro ejemplar inédito con una datación firme de inicios del siglo I a.C. hallado en La Caridad (Caminreal) (García Jiménez e.p.).
} 
inicial, puesto que si bien su influjo procede sin lugar a dudas de los modelos célticos de LT A (450-390 a.C.), su perduración únicamente se conoce por ahora en territorio peninsular ${ }^{24}$. Del mismo modo, y pese a exceder la cuestión relacionada con los escudos, podría haberse tenido en cuenta otros elementos célticos (ciertamente muy poco abundantes; cfr. Lejars 2014, 403) hallados en Sicilia; en particular el casco de hierro de Selinunte (Pernet, 2010: 25 y fig. 4) que tiene una pareja casi idéntica en Ensérune (Girard, 2013: 131 y fig. 1) y puede relacionarse con la misma problemática en un momento algo más reciente ${ }^{25}$.

La detallada y sistemática atención a los broches de cinturón calados, comúnmente asociados a las tumbas con armas de la segunda mitad del siglo V e inicios del IV a.C., representa uno de los puntos más brillantes de la obra y da con la que sin duda es la clave principal de la investigación al ahondar en lo territorial y en la distinción de las producciones locales frente a las importaciones. La importante proyección de estos objetos hacia la Italia septentrional y el Languedoc, particularmente representados en la necrópolis de Ensérune (Leconte, 1995), constituye desde hace mucho tiempo un problema historiográfico de difícil solución, que habitualmente se ha venido relacionando con movimientos de población hacia el Mediterráneo o la Europa oriental, a menudo en correlación con el fenómeno del mercenariado. La lectura de la mayoría de los broches de la periferia del mundo céltico como modelos emparentados con patrones comunes y no como importaciones, supone un distanciamiento respecto a los tradicionales análisis en relación a lo estrictamente céltico y los movimientos de población de doble sentido ${ }^{26}$. Ya se trate de broches de cinturón o de armas, el secreto radica, pues, en la atención a los detalles tipológicos, si bien no siempre es fácil distinguir algunas producciones locales de las importaciones. Del mismo modo, efectivamente los broches no siempre se hallan en relación con el armamento, y en algunos contextos incluso es más habitual hallarlos asociados a ajuares femeninos, pero también es cierto que incluso así no puede descartarse que

24 Tal como observa Baray, Quesada (2004: 77) consideraba su relación con los centros de reclutamiento de mercenarios. La conservación del patrón, prácticamente intacto, a lo largo de casi tres siglos, no es ajena al comportamiento habitual entre los pueblos peninsulares, que muestran una cierta tendencia al arcaísmo en algunas de sus armas (García Jiménez, 2012: 392-393), pero su aparente distribución en la mitad meridional de la península, lejos de las regiones más afectadas por el armamento La Tène como el nordeste, no deja de resultar misteriosa (Ibíd., 232-233). Una posibilidad atractiva sería la de la relación de estas influencias con el componente púnico. En dicho sentido, resulta llamativa la representación de escudos en la proa de un navío en el reverso distal de una moneda púnica de Cartago Nova (c. 227-209 a.C.) mostrando este tipo de umbos (Gómez de Caso, 2012: 14; vid. igualmente Villaronga, 1973: 56-58 y láms. I.IV y V) y, de nuevo, corroborando fechas avanzadas, mucho más allá de LT A, para estos formatos. La hipótesis no está exenta de problemas, como por ejemplo que los escudos ovales no están documentados con seguridad en el ámbito púnico hasta la Segunda Guerra Púnica (Quesada, 2004: 75-76), mientras que igualmente es difícil que el contagio púnico se produjera de forma tan precoz teniendo en cuenta las fechas de introducción del mercenariado céltico en los ejércitos púnicos según las fuentes (vid. supra). Otra posibilidad, relacionada o no con el mercenariado, es la de su llegada por influjo de las regiones situadas en el litoral francés (sobre la relación entre ambos territorios en esta época, cfr. Schwaller et alii, 2001: passim), aunque por el momento no existen evidencias arqueológicas de estos umbos en dicho territorio.

25 Aunque si aceptáramos la continuidad de los bivalvos célticos en la etapa de LT B1, podrían incluso ser contemporáneos. A falta de contextos para los cascos de Selinunte y Ensérune, Girard (2013b: 69) propone la datación de este último ejemplar en dicha fase, a raíz de la ornamentación del adorno temporal de estos cascos con motivos del estilo vegetal continuo. El ejemplar de Selinunte ya fue estudiado por Jacobsthal (1944: 180), quien nos informaba de su paradero en una colección privada de Berlín. El autor observó ya que las carrilleras, parcialmente conservadas, probablemente no pertenecieron originalmente a este casco, al observarse una pátina muy distinta con respecto a la calota. De hecho, es llamativo que las carrilleras corresponden a modelos itálicos, si bien su añadido pudo producirse artificialmente durante su restauración para la colección.

26 Recientemente, Stöllner (2014) ha trabajado también sobre este particular e interpreta la lectura de tales variaciones locales como el resultado de la toma de conciencia del significado social y simbólico de estos objetos y su correspondiente adaptación al substrato local. La distribución de los broches o sus patrones de influencia se produciría en un primer momento a través de una movilidad individual (en la que se incluiría a mercenarios y comerciantes) que iría dirigida a las mismas regiones en las que posteriormente se proyectarían las migraciones a gran escala, repercutiendo a su vez en sucesivas modificaciones en la tipología de los broches. 
el sesgo tuviera relación con la distinta interpretación de los patrones y su simbolismo ligados a un valor análogo como elementos de prestigio.

La cuestión de las ornamentaciones de vainas con el motivo de la lira zoomorfa, y en particular con sus primeros formatos con parejas de dragones afrontados, enlaza con la misma problemática de los broches y concuerda también con la cuestión de la primera expansión céltica, con cronologías desde la primera mitad del siglo IV a.C. (LT B1) ${ }^{27}$. El modelo corresponde en realidad a la proyección del mismo patrón iconográfico conocido en algunos tipos de broche calado $^{28}$ y nos remite a una cuestión verdaderamente interesante como es la excepcional homogeneización del armamento La Tène. Baray se muestra crítico con la idea de Rapin (2004: 27; 2007: 243) sobre la lectura de estos motivos en las vainas en relación a determinadas categorías de combatiente u oficiales, argumentando que tal constante difícilmente pudo tener la misma lectura en todo el territorio céltico independientemente de sus diferencias culturales y sociales ${ }^{29}$. Es probable que el mismo razonamiento pueda hacerse extensible a otros casos también muy claros de homogeneidad en el armamento que aparecen de forma casi simultánea en muchos lugares de la geografía europea, sin que sea fácil comprender en qué lugar tuvieron su origen, ya sea en otros diseños artísticos en las vainas o incluso en relación a los umbos de escudo, que generalmente cuentan con formas casi universales. El autor acepta la posible existencia de fratrías guerreras en la koiné céltica para explicar este fenómeno de dispersión y homogeneización de la panoplia, pero sobre todo por la importancia de los sistemas clientelares ${ }^{30}$ y el establecimiento de jóvenes guerreros pertenecientes a las élites en familias distantes, una hipótesis tremendamente sugerente que podría ponerse en relación con el testimonio de César sobre la educación de los niños galos (B.G. VI.18) y la institución del fosterage (Karl, 2005). Para Baray, sería esa red capilar, más que el mercenariado, la que explicaría la rápida difusión de las novedades armamentísticas. La complejidad del problema de la gran homogeneidad del armamento La Tène, que en palabras de Rapin (2008: 254), podría compararse a la difusión del armamento hoplítico en el Mediterráneo, revela hasta qué punto es difícil abogar por una interpretación por encima de otras. Sin duda, la rápida difusión de las armas y los elementos simbólicos a menudo relacionados con ellas solo puede tratarse de forma objetiva, tal como propone el autor, mediante la identificación de distintos focos de producción para la fabricación de estas armas, aunque también es cierto que su transformación local es normalmente bastante leve y difícil de precisar (García Jiménez, e.p.).

27 El autor avala en esta cuestión la datación de los formatos más antiguos, de dragones afrontados sobre fondo piqueteado (Ginoux, 2007: 39-41), a través del ejemplar de la sep. IB 29 de Ensérune (Schwalller et alii, 2001: 178; en efecto fechado a inicios del siglo IV a.C.), pero considera una cierta distancia cronológica con otros ejemplares de Francia, Hungría o el norte de Italia como pretexto para distanciar la cuestión respecto a las migraciones célticas y los movimientos de tropas mercenarias. Para ello, parte de la datación tardía (LT B2) en la deposición de estas armas, en otros casos faltas de contexto (Ginoux, 2007: 90-97), pero más recientemente se han venido revisando algunas dataciones (Rapin, 2008: 252-253; Lejars, 2008: 147-150) que han llevado concluir, a nuestro juicio de forma muy razonable, su fabricación en la primera mitad del siglo IV a.C., y en consecuencia en concordancia con la instalación permanente de las primeras poblaciones célticas en la Cisalpina (Lejars, 2008: 167).

28 A los que da una cierta continuidad iconográfica (Ginoux, 2007: 25-28; Stöllner, 2014: 220-221).

29 La homogeneidad en el diseño de la lira zoomorfa del diseño más simple y antiguo (Ginoux, 2007: tipo 1A) es verdaderamente excepcional. Bulard (1979) había llegado a sugerir incluso la circulación de cartones para explicar su aparente invariabilidad. Si bien la idea como tal se ha ido descartando, la superposición de calcos en algunas piezas significativas tiende a señalar muy ligeras variaciones en el diseño, siempre circunscrito en un marco de 4x $2 \mathrm{~cm}$ (Rapin, 2008: 253 y nota 27). Por el contrario, probablemente sí haya claras interpretaciones locales en las liras zoomorfas más avanzadas, típicas de LT B2 y etapas posteriores, con parejas de "dragones" o "grifos" afrontados (Ginoux, 2007; tipos 1B/2B-2F; estos últimos mezclados ya con otros motivos artísticos).

30 Sobre la importancia de las relaciones clientelares entre los pueblos célticos, véase por ejemplo: Polibio, II.17.12 y César, B.G., VI.15.2. 
A la luz de lo planteado anteriormente, se suscitan, ya en un segundo bloque, algunas cuestiones que resultan fundamentales en cualquier estudio sobre el mercenariado céltico: la relación de este con el fenómeno de las migraciones y el siempre esquivo concepto de la aculturación. Se trata en definitiva de una problemática muy unida a la cuestión de la identidad étnica, con los interrogantes y polémicas que ello conlleva, especialmente en los siempre difíciles, cuando no imposibles, intentos por determinar identidades a partir del registro material. Uno de los lugares más interesantes como foco de discusión es la necrópolis de Ensérune (Hérault / Francia), en el Languedoc occidental ${ }^{31}$; una de las necrópolis con armamento La Tène de mayor longevidad (segundo cuarto del siglo V a.C.-inicios II a.C.; Schwaller et alii, 2001: 174) a menudo concebida como un centro de reclutamiento de mercenarios (Péré-Noguès, 2007: 354; cfr. Rapin, 2008: 251 y Girard, 2013: 133; con algunos matices). Baray insiste muy acertadamente en dos cuestiones fundamentales como son la producción autóctona de las armas $^{32}$ (Schwaller et alii, 2001: 182-183; Rapin, 2004: 27-28) y la correspondencia del lugar a un entorno en el que el armamento La Tène es el más frecuente (Girard, 2013b), lo que sitúa el emplazamiento en una posición algo más compleja, que trasciende la de su simple relación con el mercenariado ${ }^{33}$. Añadiríamos también que algo parecido puede observarse en otros muchos puntos de la periferia de la cultura de La Tène que adoptaron las panoplias de matriz lateniense como la Provenza, la Liguria, la región aquitana o el nordeste de la península ibérica (García Jiménez, e.p.). La percepción del autor sobre esta impregnación, a la luz de lo anterior, es sumamente interesante: no descarta el propio mercenariado, pero le otorga un espacio complementario, supeditado a la existencia de ciertos vínculos "diplomáticos” y la circulación de tropas gestadas en el sino de las relaciones clientelares. La captación de dicho armamento se produciría, pues, mediante la agencia de las élites locales y en consonancia con el prestigio y el poder que las armas otorgan. Es ese uno de los pasajes más penetrantes del libro, al apuntar Baray que el objeto - en este caso las armas - trasciende su hipotética correspondencia étnica, ya que son las élites al escogerlo como símbolo los que le dotan de un componente identitario que los acercaría así a los grupos rectores de otros ámbitos de la Céltica.

Obviamente, Italia es el siguiente punto de discusión debido a la llegada de poblaciones inmigrantes y su manifestación arqueológica a través de distintas expresiones en la cultura material, en las que habitualmente conviven elementos latenienses típicos, en especial armamentísticos, con otros de la más pura tradición local. La búsqueda de la traza de mercenarios a través de la arqueología suele relacionarse con la presencia de armas latenienses fuera de su contexto habitual, generalmente en tumbas localizadas fuera de los territorios donde se establecieron las tribus célticas. En dicho sentido, el mismo criterio anteriormente citado es igualmente vigente, y es algo aceptado que el uso ocasional de armamento La Tène en zonas

31 Retomando la cuestión del primer mercenariado celta por parte de Cartago (v. supra), las fuentes (Hdt. VII.165) mencionan explícitamente la participación de tropas elísicas, del Languedoc, en la batalla de Himera (480 a.C.). Si bien la condición de "celtas" de estos pueblos no está clara en esta etapa, ya en el siglo IV a.C. no hay dudas de su afinidad en el uso de armamento La Tène y, si se quiere, de su pertenencia a una "koiné céltica periférica" (cfr. igualmente el caso de los ligures). La ausencia de referencias directas al reclutamiento de mercenarios en esta región con posterioridad a esta campaña, puede ser más virtual que real. Cartago tendió a explotar mayoritariamente al mercenariado hispánico o celtoitálico, de modo que el componente sudgálico pudo aparecer filtrado por los centros de reclutamiento del nordeste peninsular como Emporion (Fariselli, 2002: 270-271; Graells, 2014: 48), para los pueblos más occidentales, o el territorio ligur para el resto.

32 Lógicamente con claras excepciones como serían las falcatas y otras armas ibéricas de las fases más antiguas, el casco ya citado (probablemente), además de otros elementos de clara producción en el nordeste peninsular (e.g. la espada de la sep. 178) o incluso del interior, como indicaría la presencia de una espada La Tène hispánica con vaina enteriza y suspensión modificada; probablemente celtibérica (García Jiménez, 2012: 143 y 368).

33 De hecho, ya en el mismo sentido: Rapin y Schwaller, 1987: 180-182 y Schwaller et alii, 2001: 180-183; por lo que no es una percepción novedosa. 
periféricas no es evidencia suficiente para afirmar su relación directa con el mercenariado ${ }^{34}$. Baray aquí, al contrario que Graells, no piensa que ajuares funerarios heterogéneos, por ricos que sean, indiquen la presencia de un mercenario. Pero sin duda el mayor punto de interés de la cuestión itálica en esta obra tiene que ver con la cuestión de la presencia céltica en la región meridional de la península. La práctica ausencia de armamento La Tène en Apulia (Lejars 2014, 403) ${ }^{35}$ es en sí misma un argumento insuficiente para desechar la presencia de mercenarios en la zona, bien atestiguada por las fuentes, pero Baray lanza en este discurso una interesante crítica a la interpretación de estas referencias, que en su opinión, y en contra de la creencia habitual, no citan en ningún momento una presencia céltica estable en el territorio, sino tan solo el repetido recurso a la región para el repliegue y refugio de tropas ${ }^{36}$. De nuevo, cuando tratamos de cruzar los datos literarios con la arqueología, la cautela y la revisión detallada de toda la información a nuestra disposición es fundamental. Sin duda, la cuestión resulta mucho más atractiva al compararla con las propuestas de Graells sobre el mercenariado hispánico en la Italia meridional, que a la inversa halla en el silencio de las fuentes un flaco argumento para rechazar la presencia de mercenarios hispanos en los conflictos que allí se desarrollaron durante el siglo IV a.C.

Otro de los principales focos de atención del autor se centra en el mercenariado céltico oriental y, muy particularmente, en las estelas de Alejandría y su relación con la atribución de algunas de ellas a personajes de origen gálata. A partir de estas, de las que ofrece una detallada descripción, incluyendo fotografías y la transcripción de sus inscripciones, se enlaza con la cuestión del escudo oval y su (por otra parte evidente y conocida) trascendencia más allá de las tribus gálatas, como demostrarían entre otros indicadores las estelas de Sidón, que representan a soldados helenísticos dotados de escudos ovales con umbos metálicos ${ }^{37}$. Estos ejemplos, además de otros relacionados con pequeñas estatuillas de terracota o la presencia de escudos representados en los relieves de Petra, sirven, una vez más, como argumentos para alertar de los riesgos en la asimilación de cultura material e identidad étnica. En claro contraste con la abundante iconografía, que no pretende otra cosa que representar tropas gálatas, no importa si mercenarias, auxiliares o aliadas o si defendían los intereses de las monarquías helenísticas o los suyos propios, llama la atención la escasez de elementos arqueológicos en una región tan vasta. Hubiera sido deseable, en consecuencia, que se incidiera en los escasos ejemplos conocidos al respecto, como el de la sepultura de Lychnidos, en Macedonia (Gustin et alii, 2012), que ha sido atribuida a un mercenario celta.

En cualquier caso, más allá de la cuestión de la identidad étnica en la que tanto insiste el autor en este capítulo, la adopción de determinado tipo de armamento tendría mucho que ver con una ósmosis cultural por la que se incorporan aquellas armas más eficaces o mejor adaptadas a un cierto tipo de combate. Pero sobre todo nos quedamos con sus puntuales alusiones a la

34 Sobre el casco de Canosa, que el autor analiza, ha habido posiciones discrepantes en cuanto a su lugar de fabricación (itálica o transalpina), aunque poco a poco va cuajando un cierto acuerdo en cuanto a su producción continental y su adaptación al uso suritálico mediante la inclusión de cánulas en los laterales como soportes para plumas ornamentales (Vitali, 2008: 94; Mazzoli, 2010: 32-33). Contrariamente, no se atiende en el volumen a las tumbas de Aléria, que sólo se citan de forma fugaz, pero se insinúa con acierto que el origen de los guerreros allí sepultados pudo tener relación con el territorio ligur y quizás con poblaciones migradas, aunque no necesariamente mercenarios. Sobre esta cuestión, véase el estudio reciente de M. Lechenault (2014).

35 Tan solo el casco de Canosa (supra) y una contera de vaina procedente de Gravina (Vitali, 2008: 94-96 y figs. 1-3).

36 En el mismo sentido, véase Bourdin, 2011: 20-27.

37 Resulta chocante a este respecto que Baray señale en la pág. 82 que los griegos que combatieron contra los gálatas no modificaron sus armas ni adaptaron ninguna lateniense, cuando la adopción del thureos por los ejércitos helenísticos es sin duda fruto del contacto con el mercenariado céltico, fuese directamente fuese a partir de las campañas de Pirro en la Magna Grecia. 
circulación de tropas (a menudo mercenarias) y la constitución de un entramado de relaciones muy estable con las culturas mediterráneas, en especial las occidentales. Es importante anotar que, tal como sugiere Baray, se trata de un recurso que se imprime en el sino de relaciones sociales fluidas, que a su vez favorecen también intercambios de prestigio, de modo que raramente la arqueología puede explicar la presencia física de mercenarios como poseedores de tales objetos, pero ello no significa que en muchos casos estos intercambios no se produzcan gracias a las redes de reclutamiento. Sorprende entonces la escasa mención al papel de los circuitos comerciales en tal proceso ${ }^{38}$, sobre todo teniendo en cuenta que el mercado de mercenarios es un mercado como cualquier otro y emplea las vías comerciales tradicionales para la captación de mano de obra (Pére-Noguès, 2007: 354; Fariselli, 2002: 264-277 ${ }^{39}$ ).

El último gran bloque del libro concierne a uno de los temas más polémicos en toda publicación dedicada al mercenariado: la del retorno de los mercenarios a sus lugares de origen. En esta sección, los mismos argumentos salen de nuevo a la luz, insistiendo en que los materiales arqueológicos son difíciles de aquilatar y no pueden demostrar (ni a menudo a desmentir, añadiríamos) su correspondencia a mercenarios, por muy chocantes que parezcan sus contextos. En la mayoría de ocasiones, sin embargo, estos contextos merecen su discusión, tal y como desarrolla Graells para el caso hispánico, pese a que se defiendan hipótesis encontradas. Algunos de los casos más llamativos de los que cita Baray son los regatones con enmangue tubular y extremo de sección cuadrada (Schönfelder, 2007: 311-318, 321-322), sin duda meras coincidencias formales ${ }^{40} \mathrm{y}$ ni siquiera influencias ocasionales como las de los cascos de Rouvray y Louviers (Ibíd.: 311-312), o el curioso soliferreum de Bobigny, que indudablemente hay que relacionar con contactos a larga distancia, del tipo que fuera. En relación a la vaina de la sepultura D de Quintanas de Gormaz, a la que el autor refiere en varias ocasiones, efectivamente nos parece claro que esta se enmarca en una tradición local de la Celtiberia y es poco probable (aunque no descartable) que se trate de una importación (cfr. García Jiménez, 2012: 136-137; García Jiménez, e.p.).

Finalmente, en el último tramo de la obra se discute holgadamente acerca de la adopción e imitación de las monedas de oro de tipo macedonio ${ }^{41}$ en territorio galo, que en general se han ido relacionando con el efecto de retorno del mercenariado (Szabó, 1991: 336). La opinión del autor en esta cuestión, que nos parece muy bien fundamentada, se separa de esta teoría, que en efecto cuenta con muchas incertidumbres, para relacionar la cuestión con el prestigio internacional del que contaba esta moneda y su aprovechamiento por parte de las élites locales.

El libro de Baray es, pues, un excelente trabajo que incide fuertemente en la complejidad de las relaciones sociales y culturales a gran distancia. La buena atención a la gran movilidad de las poblaciones célticas y la rapidez en la difusión de sus armas (Rapin, 2004 y 2008: passim) no se pierde en ningún momento del foco. Las armas se conciben no solo como objetos funcionales y con frecuencia simbólicos (que también) sino sobre todo como conceptos a imitar con el mismo fin, de modo que la toma en consideración de la impregnación del armamento La Tène en determinadas regiones nos parece clave para el buen desarrollo metodológico ${ }^{42}$. Al

38 Cfr. Baray, p. 88.

39 Cfr. Graells: supra; con una opinión distinta.

40 Existen algunos ejemplos en la península ibérica, sin ir más lejos, que nada tienen que ver los unos con los otros, y mucho menos con el sauroter griego (e.g. silo 30 de Can Miralles, en el nordeste peninsular (Pujol y García Roselló, 1982-83: 89-90 y 95) o incluso sep. 28 de Las Ruedas (Sanz, 1998: 76-77) y en general en otros lugares del ámbito vacceocántabro.

41 Podrían haberse considerado también otras producciones menos debatidas, como las monedas de plata a imitación de las dracmas emporitanas de tipología púnica (Fariselli, 2002: 269-270).

42 Se insiste mucho en la obra en el desplazamiento de ideas, y no solo de personas. Esta cuestión ya la anticipaba Rapin hace ya algunos años (2004: 28) en relación a la evolución de la panoplia lateniense. 
mismo tiempo, la obra cuenta con la ventaja de recurrir a los trabajos más significativos desde el punto de vista de la discusión ${ }^{43}$, aunque adolece en muchos casos de ahondar un poco más allá y citar otros casos menos conocidos o más concretos. Si bien es cierto que su análisis no pretende ser sistemático, sino poner en tela de juicio mediante algunos ejemplos esa especie de "inercia" en la interpretación de conjuntos o materiales llamativos como pertenecientes a mercenarios, la decisión de publicar tres volúmenes en vez de uno unitario lastra un tanto la autonomía de estas páginas, pese a contar con una gran cohesión interna. Quizás podría reprochársele a esta obra el abuso de las referencias textuales a otros trabajos con la intención de rebatirlos o matizarlos; una postura quizás en exceso crítica y poco constructiva. Igualmente, se echa en falta la profundización en la región ligur y la senona, ambas muy relacionadas con el mercenariado céltico y apenas comentadas, o incluso algunas opiniones en lo relativo a los posibles centros de reclutamiento del litoral o el interior. En cualquier caso, nada de ello desmerece una obra que está llamada a tener una gran repercusión. Sin duda, en cuanto el proyecto completo llegue a su término, muchas de las incógnitas que esbozábamos quedarán perfectamente despejadas.

Estamos así ante dos obras ambiciosas, de calado profundo y con la virtud de abrir sin complejos la caja de Pandora de un tema, el del mercenariado como mecánica de interacción y contacto en el antiguo Mediterráneo, que quizás se hallaba anquilosado en viejos paradigmas poco cuestionados o apenas confirmados. Pero como hemos visto, aunque Graells y Baray han realizado una aproximación pareja, desde el registro arqueológico, sus conclusiones son divergentes. Si Graells no tiene reparos en esgrimir la equivalencia entre armas y etnicidad — “en el pasado la distinción étnica sería importante y permitiría, mejor aún: obligaría, al uso de un equipamiento particular, distintivo y reconocible" (p.195)_, resucitando la moribunda idea del fósil director, Baray huye de todo determinismo en la equivalencia entre objeto material y etnia —_"...] l'objet ne peut être envisagé comme un élément représentatif d'une culture spécifique, car on tomberait ainsi dans le piège que consiste a assimiler de manière trop systématique et superficielle culture matérielle et identité ethnique" (p. 8)—. Si el primero adivina en determinados conjuntos el ajuar de un soldado de fortuna, el segundo se muestra escéptico respecto a la posibilidad de poder establecer con el análisis del registro arqueológico la profesión mercenaria. Y si Graells entiende que los aspectos estéticos de un arma - los cascos hispano-calcídicos - pueden entenderse como indicio de organización militar, su colega francés niega que los dragones o grifos de las vainas puedan leerse en ese sentido. Sin abonarnos a una u otra percepción, cabe remarcar algo que para nosotros es un gran acierto y en lo que ambos investigadores, sin embargo, coinciden: la importancia que dan a las armas como elemento con una tremenda carga simbólica e identitaria, y como tal empuñadas, adoptadas o transformadas por las comunidades de la Céltica y de Iberia. Las armas se convierten en el mudo testigo - $\mathrm{O}$ no tan mudo, pues en manos de Graells o Baray vuelven a cantar, aunque menos letales ya que antaño - del papel dinamizador que la guerra habría jugado en el Occidente antiguo, y sirven para constatar, por su adopción y rápida dispersión, la existencia de redes de intercambio de objetos, de conocimientos y de ideas (James 2007; Pérez Rubio, 2015), una capilaridad que pensamos es la que, por ejemplo, nos permite hablar de una koiné céltica. El mercenariado sería un vector más de esa red, alimentada por otros muchos, que irían desde el comercio a las relaciones diplomáticas, los matrimonios exogámicos, los peregrinajes religiosos o las

43 Faltan algunos fundamentales, como por ejemplo los de Rapin o Lejars en el volumen dedicado a Monte Bibele (Rapin 2008; Lejars, 2008; este último ni siquiera aparece en la bibliografía pese a ser uno de los mejores especialistas en la panoplia céltica), que llevan a algunos errores en la lectura cronológica de la necrópolis (e.g. en la tiplogía de las armas de la fase antigua, donde se aprecia su correspondencia a la etapa de LT B1, desde el segundo tercio del siglo IV a.C., pese a que en algunas de las tumbas su deposición es algo posterior; Ibíd.: 149 y 165). 
migraciones pactadas. Toda una red de contactos que, en lo militar, explica la posibilidad de que fragüen expediciones de tal envergadura y a tan larga distancia como el ataque a Delfos, o la agregación de contingentes numerosos y capaces de desplazarse hasta Sicilia o la Magna Grecia. Sin necesidad ni de sobredimensionar ni de minusvalorar el papel que el mercenario desempeñó en esta tupida malla de interacciones, creemos que debe entenderse como un elemento más, pero uno importante precisamente por esa relevancia que lo militar tuvo en la definición identitaria de las élites del Occidente antiguo.

\section{BIBLIOGRAFÍA}

Anthoons, G. y Clerinx, H. (eds.) (2007): The Grand 'Celtic'Story? Proceedings of the conference held in Brussels on 19 November 2005. Belgian Society for Celtic Studies, Brussels.

Barceló, P. (1991): "Mercenarios hispánicos en los ejércitos cartagineses en Sicilia", Atti del II Congresso Internazionale di Studi Fenici e Punici (Roma, 9-14 Novembre 1987): 21-26.

Benassi, R. (2001): La pittura dei Campani e dei Sanniti. L'Erma di Bretschneider. Roma.

Bishop, M. y Coulston, J. C. N. (1993): Roman Military equipment from the Punic wars to the fall of Rome, $2^{\text {nd }}$ Edition. Oxford, 2006.

Blázquez Martínez, J. M. y García-Gelabert, M. P. (1988): "Mercenarios hispanos en las fuentes literarias y en la arqueología". Habis, 18-19: 257-270.

Bourdin, S. (2011): “ Le rôdeur devant le seuil". L'installation de garnisons étrangères sur le territoire des cités d'Italie républicaine (IVe-II ${ }^{\mathrm{e}}$ siècles av. J.-C.)», J.C. Couvenhes; S. Crouzet y S. Péré-Noguès (dirs.), Pratiques et identités culturelles des armées hellénistiques du monde méditerranéen. Hellenistic Warfare 3. Scripta Antiqua, 38. Bordeaux: 19-34.

Bourdin, S. (2012): Les peuples de l'Italie préromaine. Identités, territoires et relations inter-ethniques en Italie centrale et septentrionale (VIIIe-Ier s.av.J.-C.). Rome, École française e Rome.

Bulard, A. (1979): “Fourreaux ornés d'animaux fantastiques affrontés découverts en France”. Etudes Celtiques, XVI: 27-52.

Collis, J. R. (1996): “Celts and Politics”, P. Graves-Brown, S. Jones and C. Gamble (eds.), Cultural Identity and Archaeology. The Construction of European Communities. London, Routledge: 167-78.

Collis, J. R. (1997): “Celtic Myths". Antiquity, 71: 195-201.

Collis, J. R. (2003): The Celts. Origins, Myths \& Inventions. Tempus, Stroud.

Couvenhes, J.-C., Crouzet, S. y Péré-Noguès, S. (dirs.) (2011): Pratiques et identités culturelles des armées hellénistiques du monde méditerranéen. Actes du colloque de Tours, 23-24 mars 2007 (IIIe Hellenistic Warfare), Ausonius. Bordeaux.

Cuadrado Díaz, E. (1989): La panoplia ibérica de "El Cigarralejo" (Mula, Murcia). Murcia.

Cherici, A. (2007): "Sulle rive del Mediterraneo centro-occidentale: aspetti della circolazione di armi, mercenari e cultura", Annali della Fondazione per il Museo "Claudio Faina", XIV, Etruschi, greci, fenici e cartaginesi nel Mediterraneo centrale (Orvieto, 2007): 221-269.

Diliberto, M. y Lejars, T. (2013): "Un cas de mobilité individuelle aux IVe et IIIe s. a. C.: l'exemple des pièces de jeu d'origine italique trouvées au nord des Alpes", A. Colin y F. Verdin (dirs.), Mobilité des hommes, diffusion des idées, circulation des biens dans l'espace européen à l'âge du Fer, Actes du XXVe Colloque de l'AFEAF (Bordeaux, 2-5 juin 2011), Aquitania, supplément, 30. Bordeaux: 439-458.

Egg, M.; Goedecker-Ciolek, R.; Schönfelder, M. y Zeller, K. W. (2009): "Ein Esisenzeitlichen Prunkschild vom Dürnnberg bei Hallein, Land Zalsburg”, Jahrbuch RGZM, 56: 81-103.

Fariselli. A. C. (2002): I mercenari di Cartagine. Agorà Edizioni, La Spezia.

Gabaldón Martínez, M. (2004): Ritos de armas en la Edad del Hierro. Armamento y lugares de culto en el antiguo Mediterráneo y el mundo celta. Anejos de Gladius, 7. CSIC-Polifemo. Madrid.

García y Bellido, A. (1934): "Factores que contribuyeron a la helenización de la España prerromana I. Los iberos en la Grecia propia y en el Oriente helenístico". Boletín de la Real Academia de la Historia, 104: 639-670.

García y Bellido, A. (1964): "Moericus, Belligenus y los mercenarios españoles en Siracusa". Boletín de la Real Academia de la Historia, 150: 7-23. 
García y Bellido, A. (1974): "Otro testimonio más de la presencia de mercenarios españoles en el Mediterráneo", E. Ripoll y E. Sanmartí (eds.), Simposio internacional de colonizaciones I. (Barcelona 1971): 201-203.

García Jiménez, G. (2012): El armamento de influencia la Tène en la Península Ibérica (siglos V-I a.C.). Éditions Monique Mergoil. Montagnac.

García Jiménez, G. (dir.) (2013): Desperta Ferro Especial IV. Mercenarios en el mundo antiguo. Desperta Ferro Ediciones. Madrid.

García Jiménez, G. (e.p.): "Panoplias hispánicas con armas de influencia La Tène: las opciones de la periferia". R. Graells; y D. Marzoli (eds.), Armamento y arqueología de la guerra en la Península Ibérica prerromana (ss. VI-I a.C.): problemas, objetivos y estrategias. RGZM, e.p.

García Jiménez, G. y Graells i Fabregat, R. (e.p.): "El trofeo de Can Miralles. El silo 24 y los trofeos con armas del nordeste de la Península Ibérica”, Monographies d'Archéologie Mediterranéene, e.p.

García Jiménez, G. y Quesada Sanz, F. (2015): "Los umbos bivalvos de scuta en Iberia y la cuestión céltica", F. Burillo y M. Chordá (eds.), VII Simposio sobre los Celtíberos: Nuevos Hallazgos, Nuevas Interpretaciones. Zaragoza: 21-27.

García Roselló, J.; Zamora, M.; Pujol, J. (1998): “Armament i societat a la Laietània ibèrica”. Congreso internacional: Los iberos Príncipes de occidente. Estructuras de poder en la sociedad ibérica (Barcelona, 1998). Barcelona: 309-325.

García-Mauriño, J. (1993): "Los cascos de tipo Montefortino en la Península Ibérica. Aportación al estudio del armamento de la $\mathrm{II}^{\mathrm{a}}$ Edad del Hierro". Complutum, 4: 95-146.

Ginoux, N. (2007): Le thème symbolique de "la paire de dragons" sur les fourreaux celtiques (IVe-IIe siècles avant J.-C.), Bar International Series, 1702. Oxford.

Girard, B. (2013): " De la panoplie au guerrier: rôle des armes, statuts et symboles au Second Âge du Fer", B. Girard (dir.), Au fil de l'épée. Armes et guerriers en pays celte méditerranéen, Musée archéologique de Nîmes, Bulletin de l'École Antique de Nîmes, 30 (Nîmes 2013): 131-146.

Girard, B. (2013b): “Du fragment à la panoplie: les armements et les équipements du Second Âge du Fer". B. Girard (dir.), Au fil de l'épée. Armes et guerriers en pays celte méditerranéen, Musée archéologique de Nîmes, Bulletin de l'École Antique de Nîmes, 30 (Nîmes 2013): 63-77.

Gómez Fraile, J. M. (1999): "Mercenariado y bandolerismo en Celtiberia. Dos cuestiones desenfocadas", F. Burillo (coord.), IV Simposio sobre celtíberos. Economía. Zaragoza: 503-509.

Gómez de Caso Zuriaga, J. (2012): "El ejército cartaginés en Iberia durante la Segunda Guerra Púnica", Desperta Ferro. Antigua y Medieval, 17: 10-15.

Gracia Alonso, F. (2003): La guerra en la protohistoria. Héroes, nobles, mercenarios y campesinos, Ariel. Barcelona.

Graells, R. (2011): "Mistophoroi ilergetes en el siglo IV a.C.: el ejemplo de las tumbas de caballo de la necrópolis de la Pedrera (Vallfogona de Balaguer-Térmens, Catalunya, España)", Jahrbuch-RGZM 55: $81-158$.

Graells, R. (2014): “Discos-coraza de la Península Ibérica (s. VI-IV a.C.)”, Jahrbuch-RGZM 59: 85244.

Graells, R., Lorrio, A. y Quesada, F. (2014): Cascos Hispano-Calcídicos. Símbolo de las élites guerreras celtibéricas. RGZM Kataloge 46, Mainz.

Gustin, M.; Kuzman, P. y Malenko, V. (2012): "Ein Keltischer Krieger in Lychnidos, Ohrid, Mazedonien". Folia Archaeologica Balkanika, 2012, 2: 181-196.

Jacobsthal, P. (1944): Early Celtic Art, II vols. Oxford, 1969.

James, S. (1998): "Celts, politics and motivation in archaeology". Antiquity 72: 200-209.

James, S. (1999): The Atlantic Celts. Ancient People or Modern Invention? British Museum Publications. London.

James, S. (2007): "Iron Age paradigms and the Celtic metanarrative: a case study in conceptualising the past, and writting histories". G. Anthoons y H. Clerinx (eds.), The Grand 'Celtic'Story? Proceedings of the conference held in Brussels on 19 November 2005. Brussels: 11-31.

Karl, R. (2005): "Master and Apprentice, Knight and Squire: Education in the 'Celtic' Iron Age". Oxford Journal of Archaeology 24 (3): 255-271.

Karl, R. y Stifter, D. (eds.) (2007): The Celtic world: critical concepts in historical studies, vol. 1: Theory in Celtic studies, Routledge. London.

Knez, T. (1966): "Latenske najdbe iz Novega Mesta". Arheoloski Vestnik, XVII: 391-407. 
Leconte, S. (1995): “ Les agrafes de ceinture ajourées à Ensérune, études et comparaisons interrégionales". Etudes Celtiques, 31: 7-47.

Lechenault, M. (2014): “Dans le fracas des armes : Aléria et les mobilités guerrières en Mer Tyrrhénienne à la fin du Ive siècle av. J.-C.”, P. Barral; J.P. Guillaumet; M.-J. Roulière-Lambert; M. Saracino y D. Vitali (ed.), Les celtes et le Nord de l'Italie. Premier et Second Âges du fer. Actes du XXXVIe colloque international de l'AFEAF (Verona 17-20 maggio 2012). Revue archéologique de l'Est. Supplément, 36. Dijon: 435-442.

Lejars, T. (2008): " Les guerriers et l'armement celto-italique de la nécropole de Monte Bibele”. D. Vitali y S. Verger (eds.), Tra mondo celtico e mondo italico. La necropoli de Monte Bibele. Atti della Tavola Rotonda. (Roma, 1997): 127-222.

Lejars,T. (2014): “L'armement des celtes d'Italie”, P. Barral; J.P. Guillaumet; M.-J. Roulière-Lambert ; M. Saracino y D. Vitali (ed.), Les celtes et le Nord de l'Italie. Premier et Second Âges du fer. Actes du XXXVIe colloque international de l'AFEAF (Verona 17-20 maggio 2012). Revue archéologique de l'Est. Supplément, 36. Dijon: 401-434.

Luque Álvarez, J. (1984): "Nuevos broches de cinturón célticos (peninsulares) en Grecia y la cuestión de los primeros mercenarios ibéricos en el Mediterráneo en el s. VI a.C.”. Archivo Español del Arqueología, 57: 3-15.

Mazzoli, M. (2010): "Was macht ein keltischer Prunkhelm in Apulien? Der Helm von Canosa", M. Schönfelder (ed.), Kelten! Kelten? Keltische Spuren in italien, Verlag des Römisch-Germanischen Zentralmuseums. Mainz: 30-33.

Megaw, M. R.; Megaw Y J. V. S. (1996): “Ancient Celts and modern ethnicity”, Antiquity, 70: 175-81.

Megaw, M. R. y Megaw, J. V. S. (1998): “The mechanism of (Celtic) dreams': a partial response to our critics". Antiquity, 72: 276-9.

Naso, A. (2003): I bronzi etruschi e italici del Römisch-Germanisches Zentralmuseum, Kataloge vorund Frühgeschichtlicher Altertümer 33. Mainz.

Pelegrín Campo, J. (2004): "Celtíberos en África: en torno a un episodio de la Segunda Guerra Púnica", F. Beltrán (coord.), Antiqua iuniora: en torno al Mediterráneo en la Antigüedad. Zaragoza: 173188.

Pelegrín Campo, J. (2005): “Polibio, Fabio Píctor y el origen del etnónimo “celtíberos”. Gerión 23, n. ․ 1: 115-136.

Péré-Noguès, S. (2007): “ Les Celtes et le mercenariat en Occident (IVe et IIIe s. av.n.è)”. C. Mennessier-Jouannet; A.M. Adam y P.-Y. Milcent (eds.), La gaule dans son contexte européen aux IVe et IIIe siècles avant notre ère. Actes du XVIIe Colloque International de l'AFEAF (Clermont-Ferrand, 2003), Monographies d'Archéologie Méditerranéene. Lattes: 353-361.

Péré-Noguès, S. (2013): "Las bandas mercenarias como comunidades políticas: Sicilia",

García Jiménez, G. (dir.), Desperta Ferro Especial IV. Mercenarios en el mundo antiguo: 36-39.

Pérez Rubio, A. (2015): "Trouble Comes in threes. From Chariot to Cavalary in the 'Celtic' World", Ancient Warfare: Introducing Current Research, Vol. I, Cambridge: 172-190.

Pernet, L. (2010): Armement et auxiliaires gaulois (IIe et Ier siècles avant notre ère), Protohistoire européene, 12. Montagnac.

Peyre, C. (1992): "L'historiographie gréco-romaine et la celtisation de Bologne étrusque". D. Vitali (dir.), Tombe e necropoli galliche di Bologna e del territorio (Bologna), Cataloghi delle Collezioni del Museo civique archeologico di Bologna, 9: 7-45.

Pliego Vázquez, R. (2003): "Sobre el Reclutamiento de Mercenarios Turdetanos: el Campamento Cartaginés de El Gandul (Alcalá de Guadaira, Sevilla)". Habis, 34: 39-56.

Pontrandolfo; A. Rouveret, A. y M. Cipriani (1998): The Painted Tombs of Paestum. Pandemos, Paestum.

Pujol del Horno, J. y García Roselló, J. (1982-83): "El grup de sitges de Can Miralles-Can Modolell (Cabrera de Mar, Maresme). Un jaciment d'època ibèrica situat en la rodalia del poblat ibèric de Burriac". Laietania, 2-3: 46-146.

Quesada Sanz, F. (1991): "En torno al origen y procedencia de la falcata ibérica", J. Remesal y O. Musso (eds.), La presencia de material etrusco en la Península Ibérica. Universidad de Barcelona. Barcelona: 475-541.

Quesada Sanz, F. (1994a): "Vías y elementos de contacto entre la Magna Grecia y la Península Ibérica. La cuestión del mercenariado", D. Vaquerizo Gil (coord.), Arqueología de la Magna Grecia, Sicilia y la 
Península Ibérica. Una aproximación a las relaciones culturales en el marco del Mediterráneo occidental clásico. Actas del encuentro Internacional (Córdoba, 3-5 Marzo 1993). Córdoba: 189-242.

Quesada Sanz, F. (1994b): "Los mercenarios ibéricos y la concepción histórica en A. García y Bellido". Archivo Español de Arqueología, 162: 36-47.

Quesada Sanz, F. (1997): El armamento ibérico. Estudio tipológico, geográfico, funcional, social y simbólico de las armas en la Cultura Ibérica (siglos VI-I a.C.), Monographies Instrumentum, II vols. Montagnac.

Quesada Sanz, F. (2004): "Innovaciones de raíz helenística en el armamento y tácticas de los pueblos ibéricos desde el siglo III a.C", M. Bendala Galán; P. Moret y F. Quesada Sanz (coord.), Formas e imágenes del poder en los siglos III y II a.C. Modelos helenísticos y respuestas indígenas (Madrid 2004), Cuadernos de Prehistoria y Arqueología de la Universidad Autónoma de Madrid, 28-29 (2002-2003). Madrid: 69-94.

Quesada Sanz, F. (2005): "El gobierno del caballo montado en la Antigüedad Clásica con especial referencia al caso de Iberia. Bocados, espuelas y la cuestión de la silla de montar, estribos y herraduras". Gladius, XXV: 97-150.

Quesada Sanz, F. (2006): «Not so different: individual fighting techniques and battle tactics of Roman and Iberian armies within the framework of warfare in the Hellenistic Age», P. François; P. Moret; S. Péré-Noguès (eds.), L'Hellénisation en Méditerranée Occidentale au temps des guerres puniques. Actes du Colloque International de Toulouse (31 mars-2 avril 2005). Pallas, 70: 245-263.

Quesada, F. (2009): «Los mercenarios hispanos». M. Almagro-Gorbea (coord.), Historia militar de España. Prehistoria y Antigüedad. Laberinto, Madrid: 165-173.

Rapin, A. (1988): «Boucliers et lances », J.-L. Brunaux; A. Rapin, Gournay II. Boucliers et lances. Dépôts et trophées. Errance, Paris: 7-135.

Rapin, A. (2004): «Pratiques funéraires des cultures du Deuxième Âge du Fer laténien. Le problème des cartes archéologiques», L. Baray (dir.), Archéologie des pratiques funéraires. Approches critiques. Actes de la Table Ronde (Glux-en-Glenne, 2001), Bibracte, 9: 21-36.

Rapin, A. (2007): «L'armement laténien aux IVe et IIIe s. av. J.-C. en Europe», C. Mennessier-Jouannet; A.M. Adam; P.-Y. Milcent (eds.), La gaule dans son contexte européen aux IVe et IIIe siècles avant notre ère. Actes du XVIIe Colloque International de l'AFEAF (Clermont-Ferrand, 2003), Monographies d'Archéologie Méditerranéene. Lattes: 241-253.

Rapin, A. (2008): «Les Celtes et leurs voisins septentrionaux: nouveaux outils d'analyses pour l'armement laténien du sud de l'Europe aux Ve et IVe s. av. J.-C.», D. Vitali; S.Verger (eds.), Tra mondo celtico e mondo italico. La necropoli de Monte Bibele. Atti della Tavola Rotonda (Roma, 1997): 237-268.

Rapin, A.; Schwaller, M. (1987): «Contribution à l'étude de l'armement celtique: La Tombe 163 d'Ensérune (Hérault)», Revue Archeologique du Narbonnaise, 20: 155-183.

Ruiz Zapatero, G. (2004): «¿Quiénes eran los celtas?: Disipando la niebla: mitología de un» collage» histórico"», M. Almagro-Gorbea; M. Mariné; J. R. Álvarez-Sanchís (eds.), Celtas y vettones. Ávila: 72-93.

Ruiz Zapatero, G. (2010): «Roma conquistó la Galia... y Astérix y Obélix conquistaron el mundo. Desenmarañando a los celtas», $\mathrm{M}^{\mathrm{a}} \mathrm{C}$. Cardete (ed.), La Antigüedad y sus mitos. Narrativas históricas irreverentes. Madrid: 97-114.

Sanmartí, J. (1994): «Eléments de type laténien au nord-est de la Peninsule Ibérique », L'Age du Fer en Europe sud-occidentale. Actes du XVIe Colloque de l'AFEAF (Agen 1992) Aquitania, XII: 336-351.

Santos Yanguas, N. (1980): «Los celtíberos en los ejércitos romanos de época republicana», Celtiberia, 60: $181-201$

Santos Yanguas, N. (1981): «Los celtíberos en los ejércitos cartagineses», Celtiberia 60: 51-72.

Santos Yanguas, N. y Montero Honorato, M. P. (1982): "Los celtíberos, mercenarios de otras poblaciones ibéricas". Celtiberia, 63: 5-16

Sanz Mínguez, C. (1998): Los vacceos. Cultura y ritos funerarios de un pueblo prerromano del valle medio del Duero. La necrópolis de Las Ruedas, Padilla de Duero (Valladolid), Memorias. Arqueología en Castilla y León, 6. Salamanca.

Schönfelder, M. (2007): "Zurück aus Griechenland-Spuren keltischer Söldner in Mitteleuropa". Germania, 85: 307-328. 
Schwaller, M.; Marchand, G.; Lejars, T.; Orliac, D.; Rapin, A. y Sanmartí, E. (2001): "Échanges, influences, producttions dans la nécropole du deuxième Age du Fer d'Ensérune (Hérault)", Documents d'Archéologie méridionale, 24: 173-184.

Stöllner, M. (2014): "Mobility and cultural change of the early celts : La Tène openwork belt-hooks north and south of the Alps", P. Barral; J.P. Guillaumet; M.-J. Roulière-Lambert; M. Saracino; D. Vitali (ed.), Les celtes et le Nord de l'Italie. Premier et Second Âges du fer. Actes du XXXVIe colloque international de l'AFEAF (Verona 17-20 maggio 2012). Revue archéologique de l'Est. Supplément, 36. Dijon 2014: 211-230.

Szabó, M. (1991): “Mercenariat”. S. Moscati; O.H. Frey; V. Kruta; B. Rafetery; M. Szabó (coords.), Les Celtes. Paris: $332-336$

Tagliamonte, G. (1994): I Figli di Marte. Bretschneider. Roma.

Vassallo, S. (2014): "Un'offerta di schinieri di un mercenario iberico nella battaglia di Himera del 480 a. C.", Sicilia Antiqua XI, Studi in onore di Graziella Fiorentini: 533-540.

Villaronga, L. (1973): Las monedas hispano-cartaginesas. Barcelona.

Vitali, D. (2003): "Un inedito scudo celtico su una kelebe volterrana”, D. Vitali, L'immagine tra mondo celtico e mondo etrusco-italico. Aspetti della cultura figurativa nell'antichità. Bologna: 75-83.

Vitali, D. (2008): “Celti e Greci in Italia", D. Vitali (ed.), I Celti e il mondo greco (Ravenna, 1997). Ocnus, 8: 297-306. 